\title{
@creative
}

BY-NC-SA 4.0

UMÁTICA. Revista sobre Creación y Análisis de la Imagen

\section{$10+1$ cosas que aprendí en documenta}

\section{Diego DíEZ}

diegodiezp@gmail.com

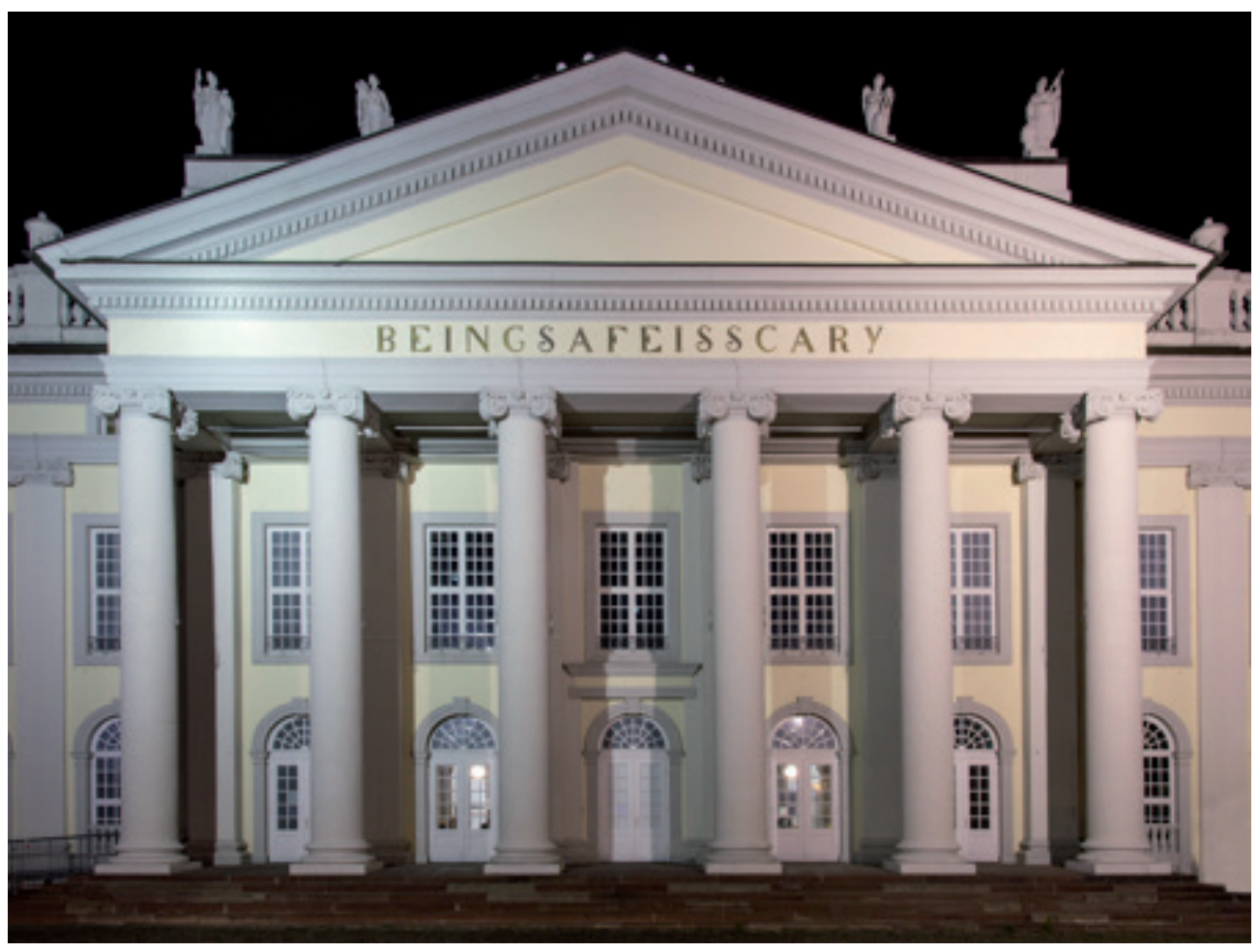

Fig.o1.

Banu Cennetoğlu

BEINGSAFEISSCARY

(2017)

Ten aluminum letters borrowed from the Fridericianum and six letters cast in brass after the existing ones

Based on graffiti existing on a wall at the National Technical University of Athens as of

April 6, 2017 $57.5 \times 1085 \times 1 \mathrm{~cm}$ overall

Co-produced with Kunstgiesserei St.

\section{Más poesía y menos ostentación}

Durante los 100 días que duró la documenta en Kassel dos obras competían constantemente por la atención de los que llegaban a Friedrichsplatz. Pese a que el Partenón de Libros de la argentina Marta Minujín fuera posiblemente la obra más compartida en re- des sociales no podemos olvidar la preciosa pieza de Banu Cennetoğlu, que cambió las letras del Fridericianum para enviarnos un mensaje de lo más actual en un mundo en constante estado de emergencia, en vez de recuperar una obra de los 80 con mucha menos fuerza vigente.

CÓMO CITAR ESTE TRABAJO / HOW TO CITE THIS PAPER

Diéz, D (2018). 10+1 cosas que aprendí en Documenta. Umática. Revista sobre Creación y Análisis de la Imagen, 1: 195-206. http://www.revistas.uma.es/index.php/umatica/issue/current 


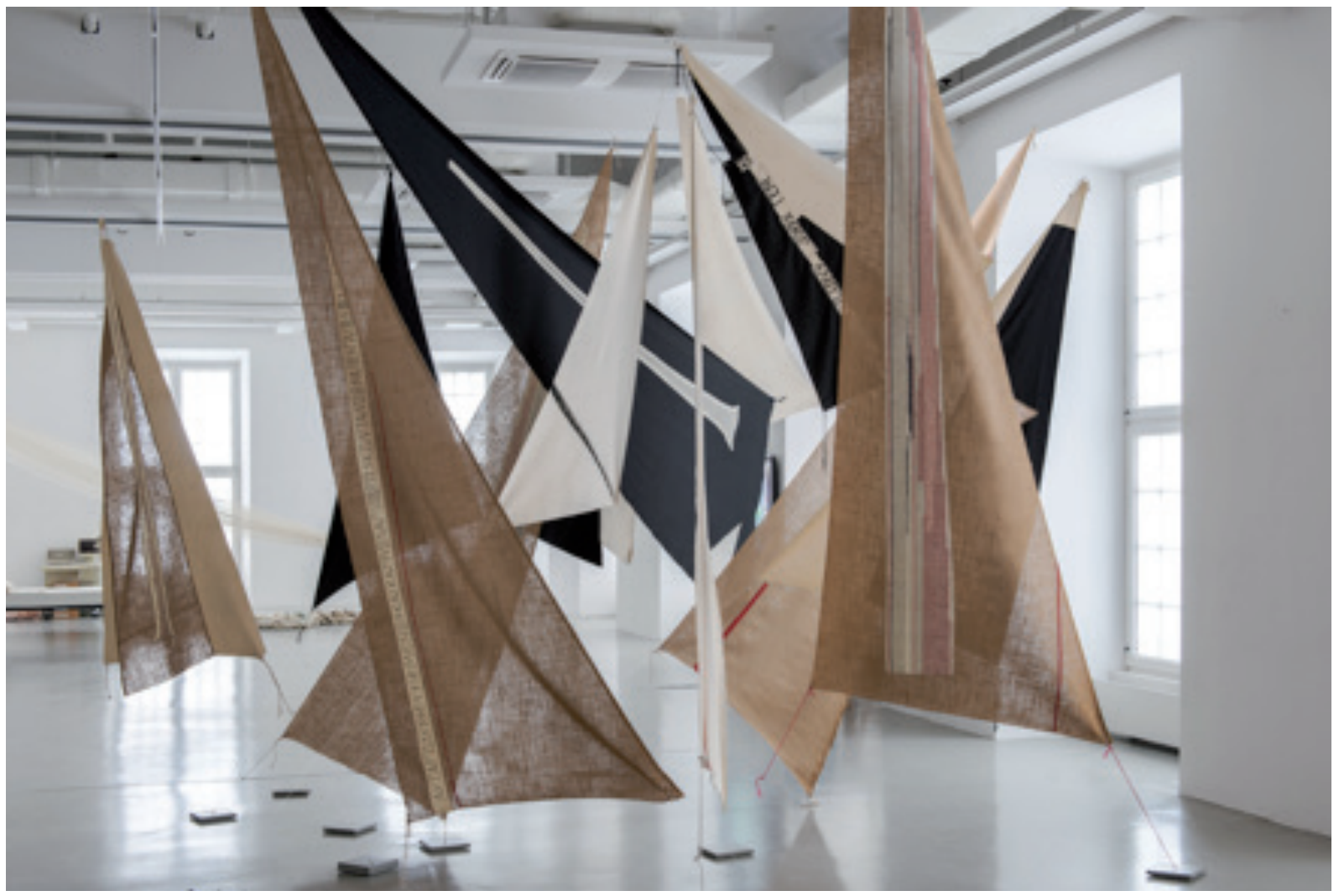

2. ¿Exposiciones que son obras?

Fig.o2. Este año, en el que suele ser el centro de la

Collection National Museum of Contemporary Art, Athens (EMST), installation view, ANTIDORON. The EMST Collection, Fridericianum, Kassel exposición, el museo Fridericianum, se produjo algo quizás inesperado. Adam Szymczyk deja el espacio clave al EMST, el Museo Nacional de Arte Contemporáneo de Atenas, para que su directora y comisaria de la exposición, Katerina Koskina, muestre algunas de las piezas de la colección, ayudando a entender mejor la realidad griega pero a la vez desplazándonos de contexto, bajo mi punto de vista, de una forma un pelín brusca. Me gusta ver esta exposición como una obra del propio Szymczyk, que al tomar prestado el EMST para su despliegue en la ciudad helena tiene que devolverles el favor con esta presentación. 


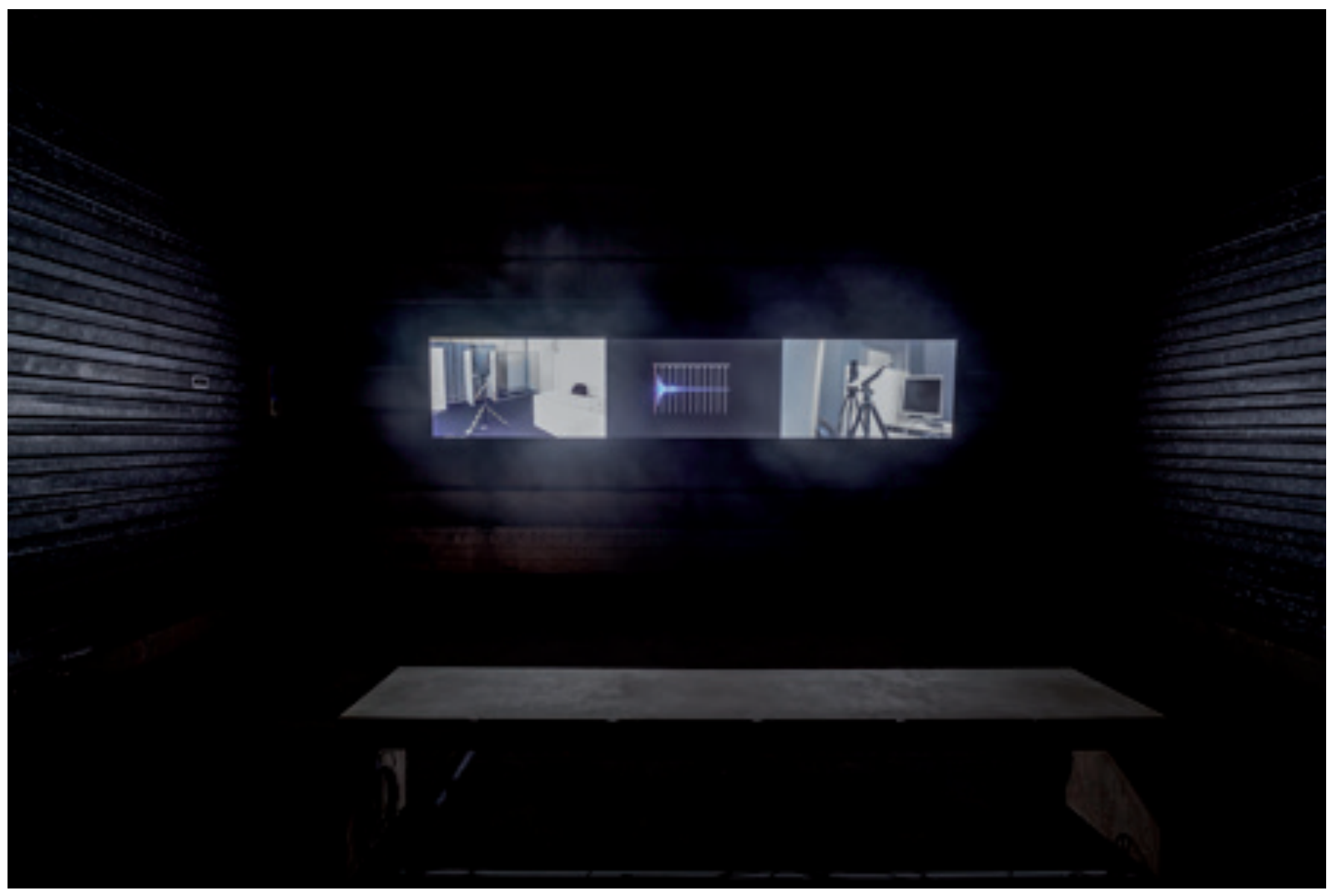

\section{Al límite}

En la Neue Neue Galerie se presenta uno de los trabajos que, quizás, más han dado que hablar esta edición. Este es la investigación que Forensic Architecture en colaboración con The Society of Friends of Halit hizo sobre la muerte de este chico de 21 años en 2006 en la ciudad de Kassel a las manos de Nationalsozialistischer Untergrund (NSU), un grupo de extrema derecha alemán que hizo en el joven Halit su novena víctima. Forensic Architecture se definen como un grupo de investigación que usan la arquitectura para tratar diferentes temas, presentando en esta documenta, casi seguro, una de las obras de arte más objetivas.
Fig.o3.

Forensic Architecture

77sqm_9:26min - Video, 2017. Three

channel video, installation view,

Neue Neue Galerie (Neue Hautpost), Kassel 


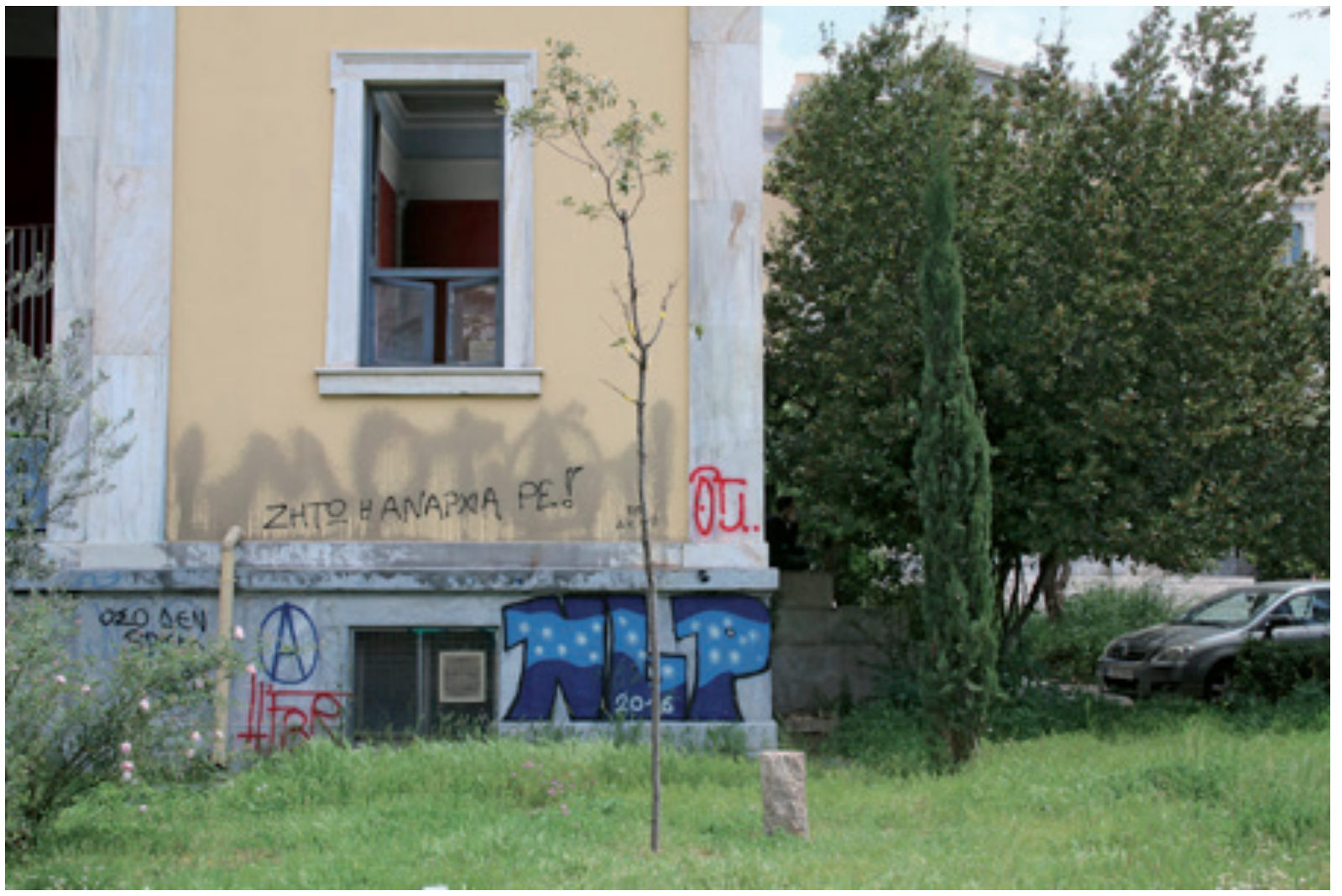

\section{Hablando con la historia}

Fig.04 Entre mis obras favoritas de la exposición se

Sokol Beqiri,

Adonis, 2017, Oak tree next to Prevelakis Hall with branches grafted from an oak in Kassel; marble, Athens, documenta 14. encuentra esta obra que se repite en Kassel y Atenas sin llegar a ser la misma. Un pequeño gesto del artista kosoves que se apropia de los famosos robles que Joseph Beuys plantó por toda Kassel en la documenta 7 de 1982. La obra, situada a la entrada de la sala permanente dedicada al artista alemán en la Neue Galerie nos propone, de una forma muy romántica y poética una insurrección ante la permanente y constantemente presente obra de Beuys y las posibilidades de trasladar esta obra a otros lugares (como ya hizo él, aunque esta vez, sin permiso) 


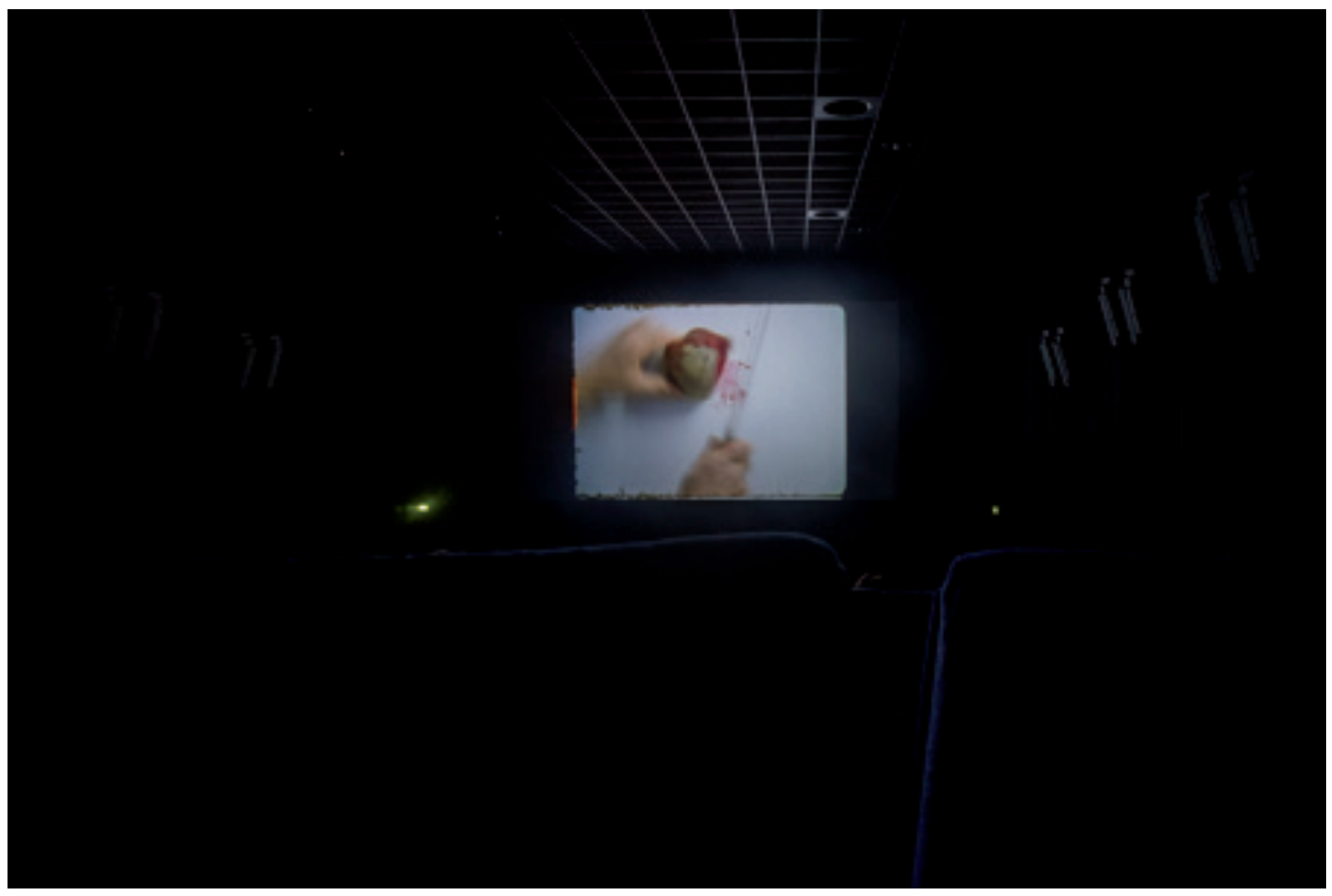

\section{Pinceladas y pinceladas}

Si entendemos la documenta como un cuadro, y cada una de sus obras como una pincelada del mismo, no podemos si no darle más importancia a unas pinceladas que a otras, como en toda pintura. $Y$ es que hay pinceladas que podrían incluso ser un cuadro aparte, por la calidad de las mismas. Una de ellas es la fantástica película de Douglas Gordon sobre Jonas Mekas, acertadamente proyectada en un cine que permite ver la obra tranquilamente y sin distraernos por la necesidad de seguir un recorrido.
Fig.05.

\section{Douglas Gordon}

I Had Nowhere to Go: A Portrait of a Displaced Person (2016)

Digital video transferred from Super 8 film and video, color and black, sound.

$97 \mathrm{~min}$. 


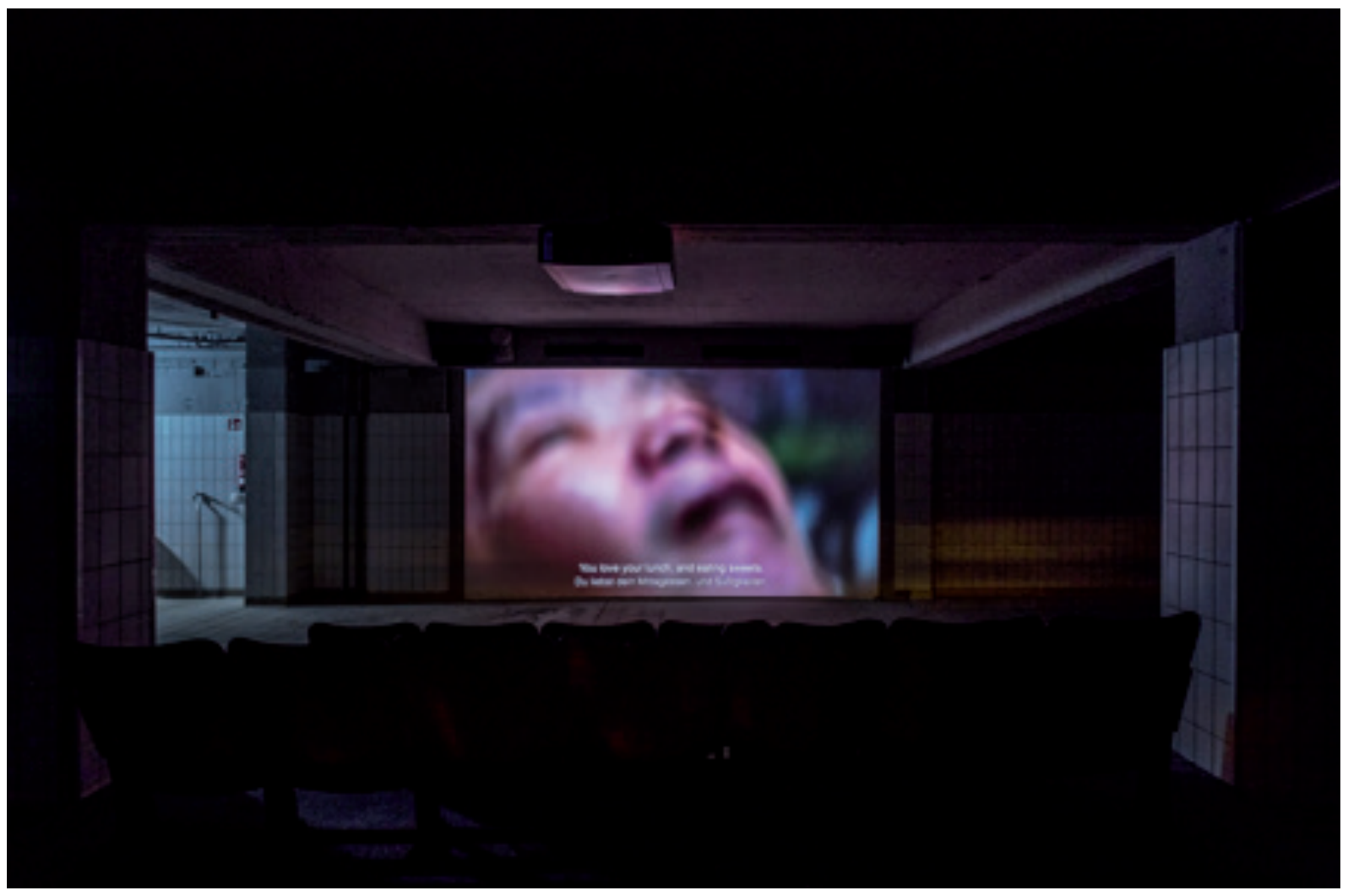

\section{6. "Falsos" documentales}

Quizás fue un gesto común el de las piezas que de alguna forma partían de hechos reales y luego se transformaban y tomaban licencias creativas del mundo de arte, en el que la documenta sigue enmarcado. Quizás las dos piezas más representativas de esto que comento fueron la de Douglas Gordon y la de Véréna Paravel \& Lucien Castaing-Taylor. He leído críticas, sobretodo al primero, por tener la oportunidad de contar la historia de Jonas Mekas y decidir no realizar un documental convencional sobre el holocausto.
Otra historia apasionante que se convierte en una película casi escultórica fue la que se podía ver en Tofufabrik sobre la historia de Issei Sagawa, un japonés que fue acusado de asesinato y canibalismo durante su estancia en Francia en 1981. Sin ninguna duda una de las obras más trastornadoras de esta documenta, tanto visualmente como la historia detrás.

Fig.o6

Véréna Paravel and Lucien Castaing-Taylor

Commensal, 2017, installation view,

Tofufabrik, Kassel, documenta 14 


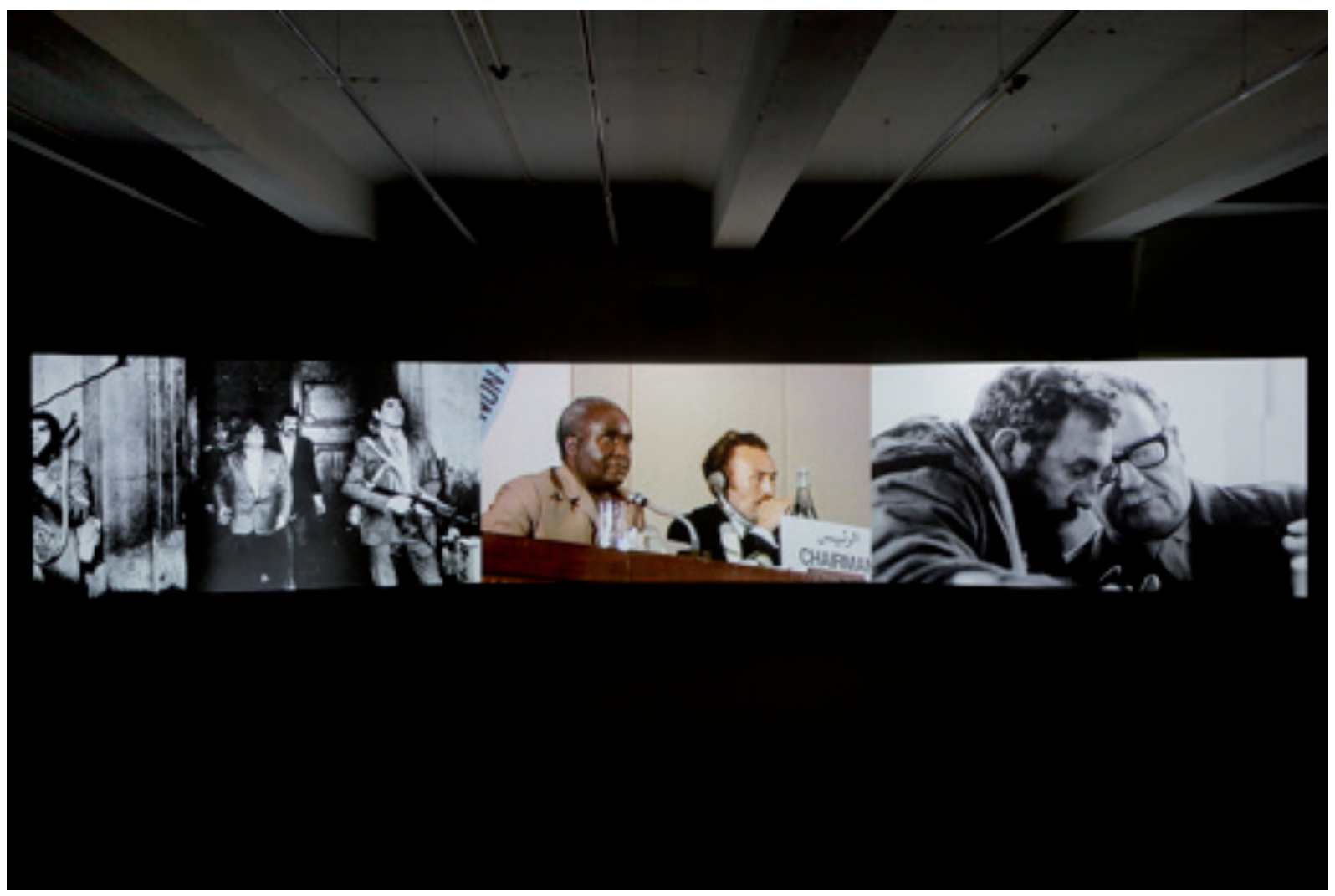

\section{Hay otras opciones, aunque no siempre funcionan}

Quizás una obra que ha servido para darnos cuenta de las intenciones a posteriori de esta documenta 14 es la de Naeem Mohaiemen. Una videoinstalación que explora el lugar histórico de Bangladesh desde la perspectiva socialista del encuentro del Movimiento No Alineado (NAM) de 1973 en Argelia a su contrapunto ideológico, el surgimiento de una fuerte perspectiva islámica en la reunión de la Organización de Países Islámicos (OIC) de 1974 en Lahore. Centrado en la navegación de Bangladesh en estas dos reuniones históricas, así como en su lucha por el reconocimiento de las Naciones Unidas (vetado por China, que actúa como representante de Pakistán), el proyecto considera la erosión de la idea del Tercer Mundo como un espacio potencial para el descolonialismo, teología de la liberación y socialismo. Documenta intentando proponer un nuevo futuro global y en concordia contra el capitalismo (al menos en el arte) pero dándose de bruces contra todas las demás fuerzas que componen este sistema.

Fig.07.

Naeem Mohaiemen

Two Meetings and a Funeral, 2017, three-channel digital video installation, Hessisches Landmuseum, Kassel 


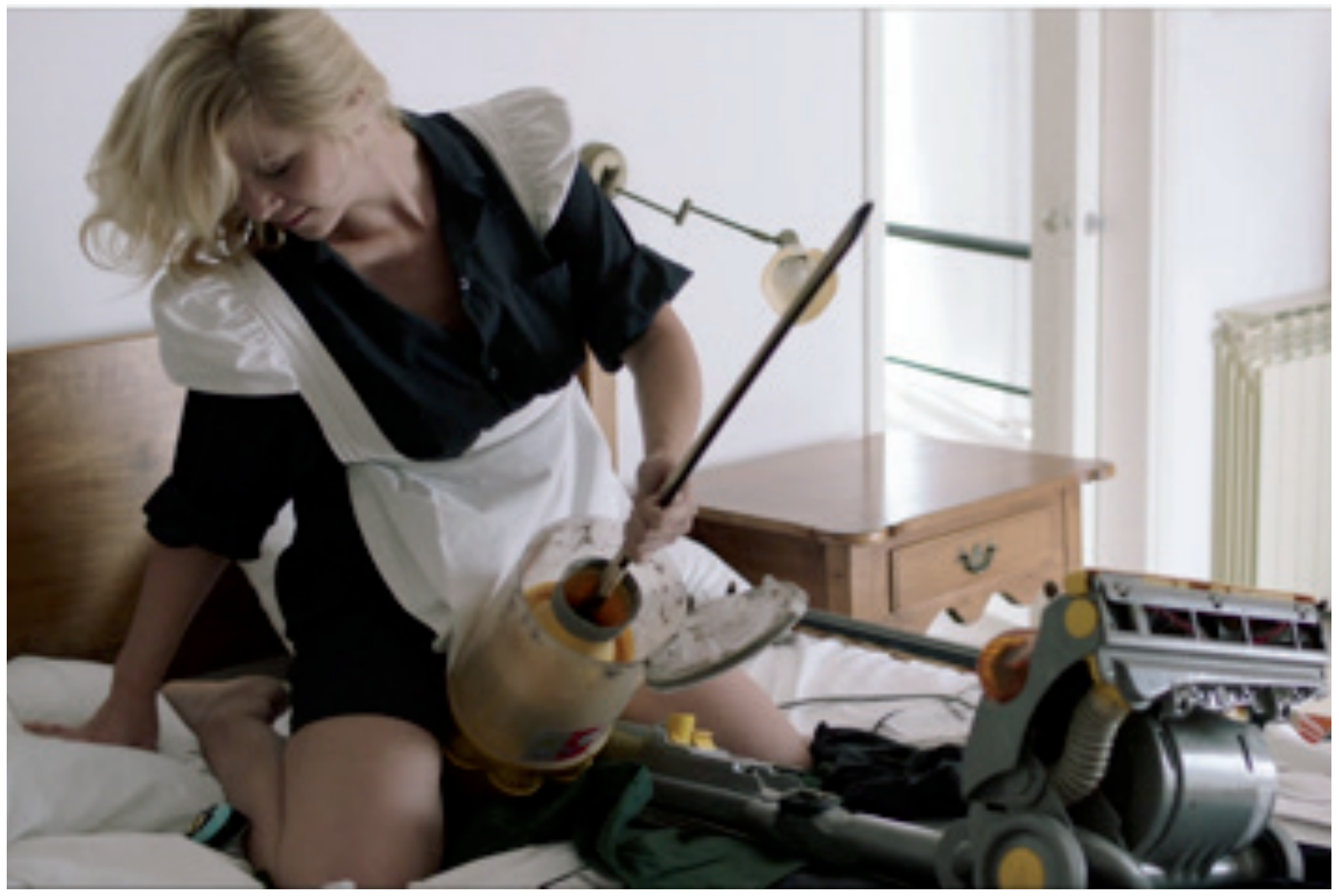

\section{Un poco de humor}

Fig.08. Fue de agradecer en una documenta que se

Roee Rosen

The Dust Channel, 2016, digital video, installation view, Palais Bellevue, Kassel planteaba tan seria y comprometida encontrar una obra como la del israelita Roee Rosen. Una opereta con un libreto ruso que se desarrolla en el ambiente doméstico de una familia de Israel que le tiene pánico al polvo. Rosen asocia el polvo con la arena y la arena con el desierto, donde Israel tiene una de las prisiones más conflictivas, donde envía a ciudadanos africanos que llegan al país buscando asilo. Una obra en la línea conceptual y política que marca la documenta pero con toques de humor que la hacen accesible a cualquiera. 


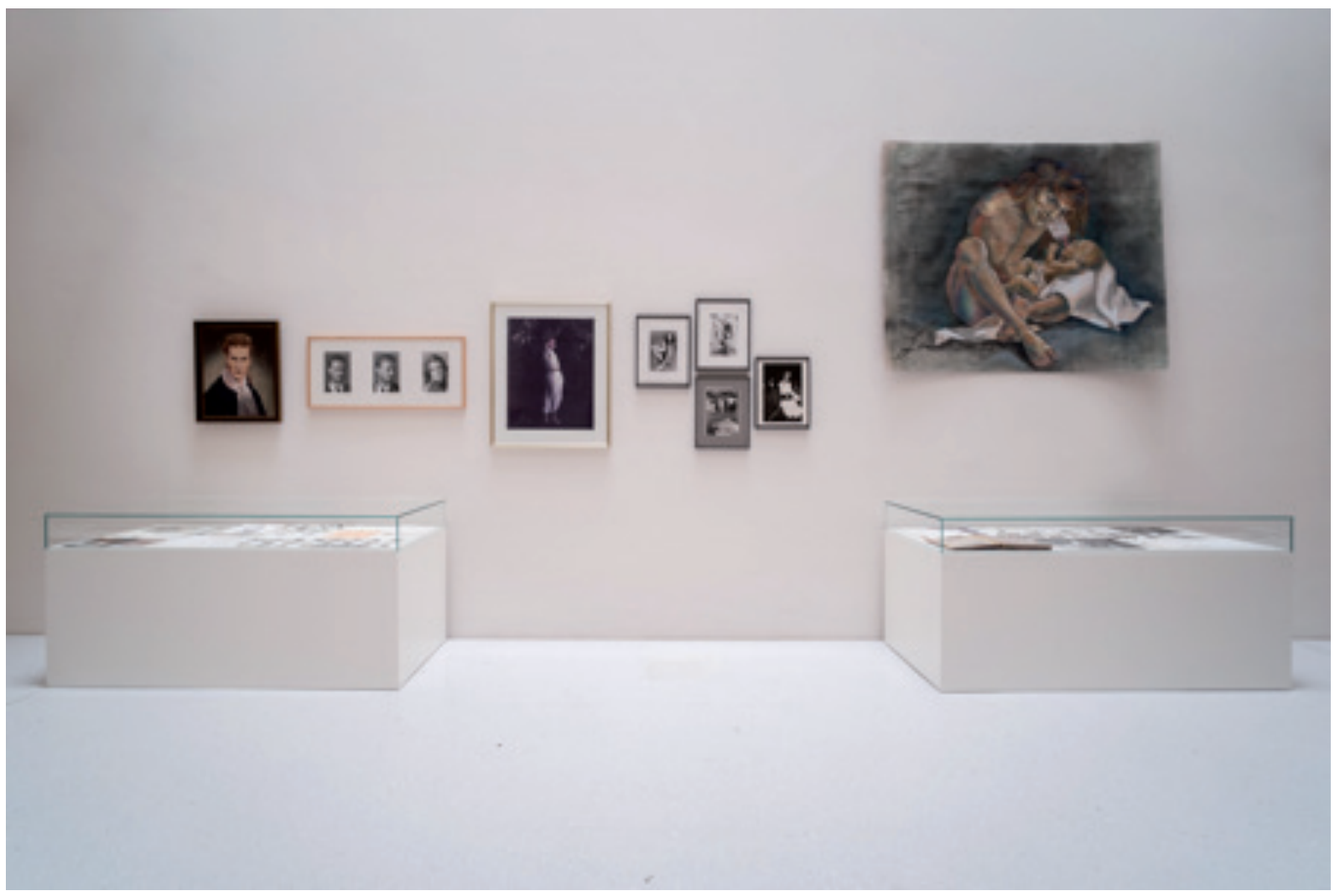

\section{Historias que necesitan ser contadas}

Una de las historias que más me tocó en mi paseo por Kassel fue la de Lorenza Böttner. Lorenza, que nació en Chile antes de la dictadura bajo el nombre Ernst Lorenz Böttner sufrió un accidente que le hizo perder los dos brazos. Se mudó a Alemania donde estudió arte en la universidad de Kassel y posteriormente en NY. Como artista realizaba cuadros con sus pies, como un fantástico autorretrato que se puede ver en la Neue Galerie, pero realmente toda su vida podría ser considerada su obra. Muchas más figuras como la de Lorenza deben ser encontradas y recuperadas para la historia del arte y en particular en el caso de Lorenza para la historia queer, y creo que en esa línea la documenta ha hecho una gran labor.
Fig.09.

Lorenza Böttner

Installation view, Neue Galerie, Kassel, documenta 14 


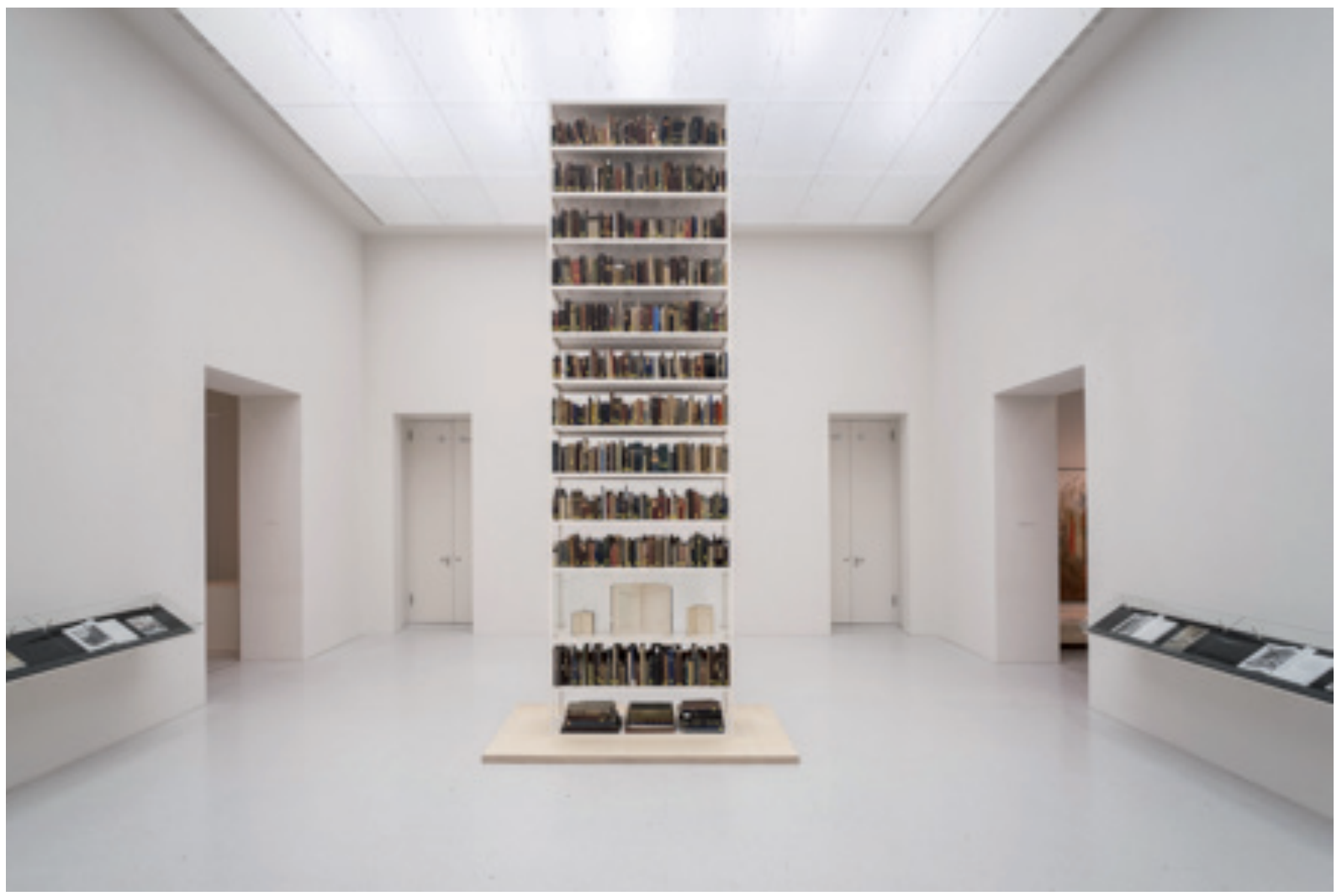

10. Vida después de documenta

Fig.10- Es quizás tan interesante como necesario

"Unlawfully acquired books from Jewish ownership" (2017) installation view, Neue Galerie, Kassel, Documenta 14, (C) Maria Eichhorn/VG BildKunst, Bonn 2017, photo by Mathias Völzke) el encontrar trabajos o proyectos que buscan tener vida antes y después de la exposición. Quizás en el caso de esta documenta el más ejemplar sea la contribución de Maria Eichhorn, que ha propuesto la creación de un instituto de investigación de todo el arte que fue adquirido de forma ilícita durante el régimen nazi. Una gran parte de este proyecto se centra en el descubrimiento de la Colección Gurlitt, pero lo expuesto son libros que provienen de diferentes bibliotecas y dueños. Un proyecto de muchas capas y muchas posibilidades que en esta documenta utiliza una enorme estantería repleta de libros como perfecta imágen de toda la propuesta curatorial. 


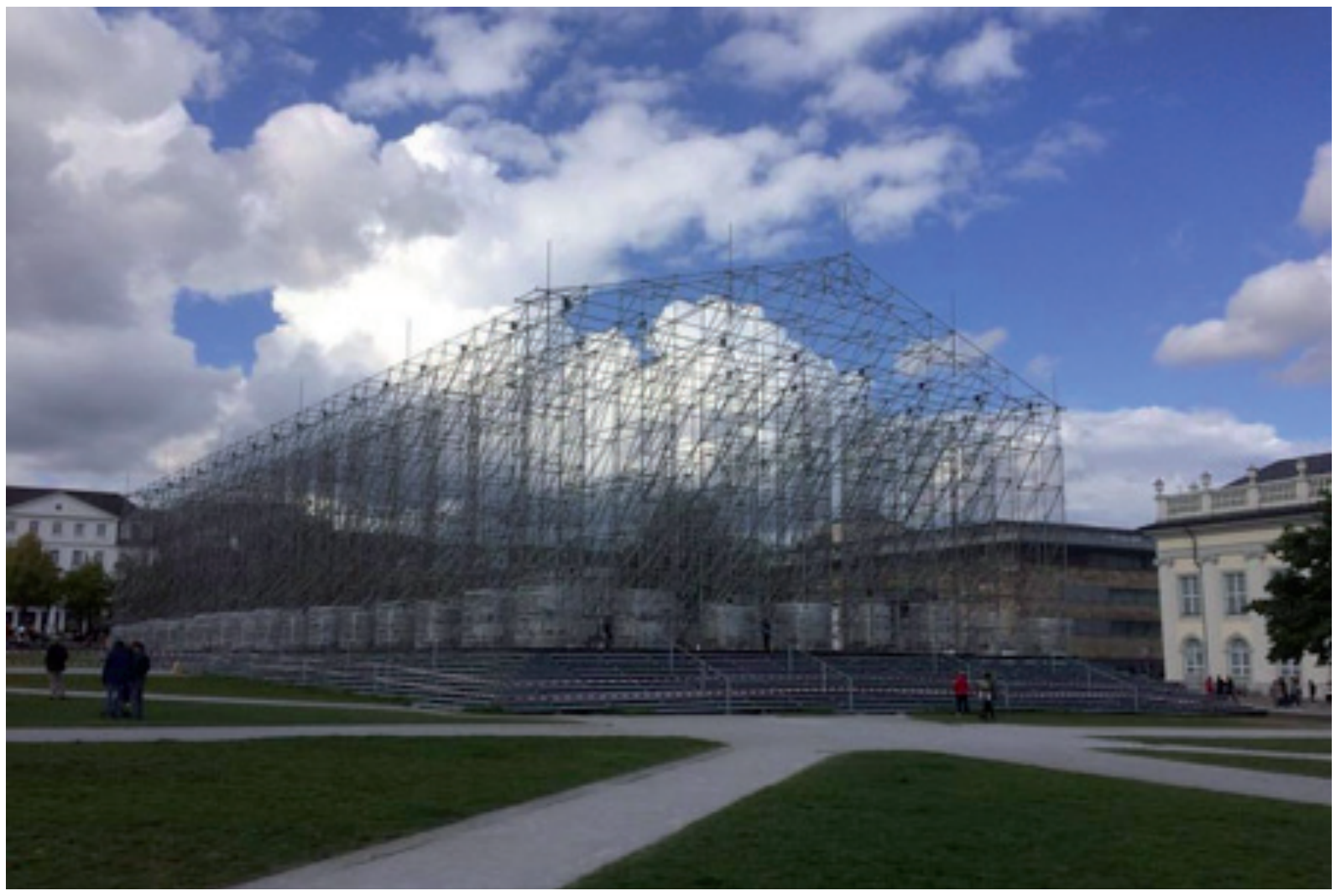

10+1: ¿A dónde nos dirigimos?

Para acabar me gustaría citar unas palaFig.11. bras de Manuel Borja-Villel en el simposio celebrado en el Van Abbe Museum de EindVista del Partenón de Libros de Marta hoven a finales de Septiembre y titulado Minujín el último día de la documenta14 "Collections in Transition: Decolonising, Demodernising and Decentralising?" como director de L'Internationale reconocía que con sus acciones quizás no sepan exactamente hacia donde se dirigen, pero si saben que no les gusta de donde vienen. Me gustaría interpretar así esta Documental4, como una documenta que permitirá a la siguiente una visión del mundo y el arte completamente diferente.

I Para consulta: https://vanabbemuseum.nl/en/programme/programme/collections-in-transition/ 
AUtOR: DIEGo DíEZ es cofundador del espacio Plət- situado en Amsterdam junto con Dieuwertje Hehewerth. Diego Diez (Barcelona, 1994) trabaja entre Países Bajos y España. Artista visual y fotógrafo. Su investigación cuestiona la idea de representación y la producción de sentido a través del uso de los sistemas de conocimiento existentes. Su trabajo abarca desde la instalación, la escultura y la fotografía hasta el diseño editorial, la intervención y la gestión cultural.

diegodiezp@gmail.com 